\title{
Anesthésic Managment of A Pregnant Woman With Cerebral Arteriovenous Malformation: A Case Report
}

Mehdi Samali (MD) ${ }^{*}$, Said Khallikane (MD), Mohammed Rabi Andaloussi (MD), Amine Meskine (MD), Abdelghafour Koundi (MD), Mustapha Bensghir (PhD)

Department of Anesthesiology and Intensive Care, Military Hospital Mohammed V Rabat, Faculty of Medicine and Pharmacy of Rabat, University Mohammed V Rabat, Morocco

DOI: $\underline{10.36347 / \text { sjmcr.2020.v08i10.019 }}$

| Received: 29.09.2020 | Accepted: 13.10 .2020 | Published: 30.10 .2020

*Corresponding author: Samali Mehdi

Abstract

Case Report

Cerebral arteriovenous malformations (AVM) are rare in pregnancy, Intracranial hemorrhage due to rupture of an AVM during pregnancy can have serious consequences on the health of the mother and the fetus. We report the case of a pregnant woman with AVM presented to our hospital at 39th week of Gestationnnel age, and Caesarean section under general anesthesia was performed successfully. Conclusions: Patients with symptomatic AVM during pregnancy are challenging in terms of medical approach in general, and of anesthetic management in particular. in the absence of consensus the anesthetic technique should be discussed on a case-by-case.

Keywords: Anesthésic, pregnant, cerebral, arteriovenous malformation.

Copyright $\odot 2020$ The Author(s): This is an open-access article distributed under the terms of the Creative Commons Attribution 4.0 International License (CC BY-NC 4.0) which permits unrestricted use, distribution, and reproduction in any medium for non-commercial use provided the original author and source are credited.

\section{INTRODUCTION}

Cerebral arteriovenous malformations (AVM) are rare in pregnancy [1]. They present in approximately $1 / 10.000$ of the population and are responsible for approximately $10 \%$ of subarachnoid hemorrhages in general population [2]. Intracranial hemorrhage due to rupture of an AVM during pregnancy is a very rare but can have serious consequences on the health of the mother and the fetus [3]. The choice of anesthetic technique for Caesarean section of these patients is made to maintain a stable cardiovascular system [4], but due to the rarity of this condition, no definitive guidelines exist.

\section{CASE PRESENTATION}

We report the case of anesthetic management of Caesarean section of a pregnant woman with AVM. A 24-year old primipara, (weight $78 \mathrm{~kg}$, height $175 \mathrm{~cm}$ ), presented to our hospital at the 22 week of gestational age (GA), with a sudden severe headache without nausea or vomiting, clinical examination finds a conscious patient, GCS :15/15, a right hemiparesis with a muscular strength rated $3 / 5$ and $4 / 5$ respectively at the upper right and lower right limb.

A cerebral magnetic resonance imaging revealed a deep parietal hematoma centered on the thalamus and adjacent cerebral peduncle occurring on AVM (Figure-1), and AVM nidus made up of multiple small serpiginous arterioles in the center of the hematoma (Figure $2 \& 3$ ).

The radiologists decided to perform angiography and endovascular operation for treatment after the termination of pregnancy; however, the patient refused the termination of the pregnancy. The treatment of AVM was postponed until after the end of pregnancy. There were no further problems during the rest of the pregnancy. The patient was admitted to the hospital with a slight monoparosis of the right lower limb at the 39th week of GA urgently with uterine contractions. Anesthesiologist, a neonatologist and obstetrician urgently reviewed the case, then it has been decided to realise Caesarean section under general anesthesia . Her American Society of Anesthesiologists Physical Status classification was I, her Mallampati classification was I, and she had a good mouth opening. On arrival in our operating room, Maternal monitoring consisted first of standard monitoring, non invasive blood pressure (BP) monitoring with five-lead electrocardiography and pulse oximetry, then radial arterial line invasive arteriel blood pressure was placed for continuous monitoring of arterial BP and collection of arterial blood for blood gas analysis during surgery. The patient's basal values were BP 120/60 mmHg, HR 78 beats per minute and peripheral capillary oxygen saturation of $99 \%$ while breathing room air. Intravenous access was secured with two 18-gauge intravenous cannulae, and the patient was given $10 \mathrm{ml} / \mathrm{kg}$ of isotonic 
saline solution. Antiprophylaxis with $2 \mathrm{~g}$ of amoxicillin and clavulanic acid. After 5 minutes of preoxygenation with $100 \%$ oxygen, anesthetic was induced with propofol $(2 \mathrm{mg} / \mathrm{kg})$, succinylcholine $(1 \mathrm{mg} / \mathrm{kg})$, fentanyl $(1,5 \mu \mathrm{g} / \mathrm{kg})$ was administered to facilitate tracheal intubation with intravenous lidocaine $(1 \mathrm{mg} / \mathrm{kg})$ were used to reduce the hypertensive response to tracheal intubation. Immediately after intubation, the patient's BP was $120 / 65 \mathrm{mmHg}$, and her HR was 85 beat per minute. Anesthésia was maintained with propofol until the delivery of the infant. The Apgar score was 8/10 and $10 / 10$ at the 1 st and the 5th minutes. After the delivery, anesthesia was maintained with rocuronium $(0.3 \mathrm{mg} / \mathrm{kg})$, fentanyl $(3 \mu \mathrm{g} / \mathrm{kg})$ and propofol in Targetcontrolled intravenous anesthesia, with continuous monitoring of blood pressure to ensure better hemodynamic stability and infusion with air/O2 (\%5050). The patient was mechanically ventilated with a target tidal volume of $480 \mathrm{ml}$ and a respiratory rate of 12 breaths per minute to maintain normocapnia (end tidal expiratory $\mathrm{CO} 2$ approximately $35 \mathrm{mmHg}$ ). Following the completion of surgical procedures, Postoperative analgesia consisted of intravenous paracetamol $1 \mathrm{~g}$ every 8 hours and intravenous nefopam $100 \mathrm{mg}$ per 24 hours the patient was extubated before being awakened. Her ventilation was assisted via a mask until she was able to breathe without any support. The patient was continuously monitored for another 24 hours in the intensive care unit, and the postoperative period remained uneventful. One week later, angiography and endovascular operation were performed successfully and than the patient was discharged in good condition.

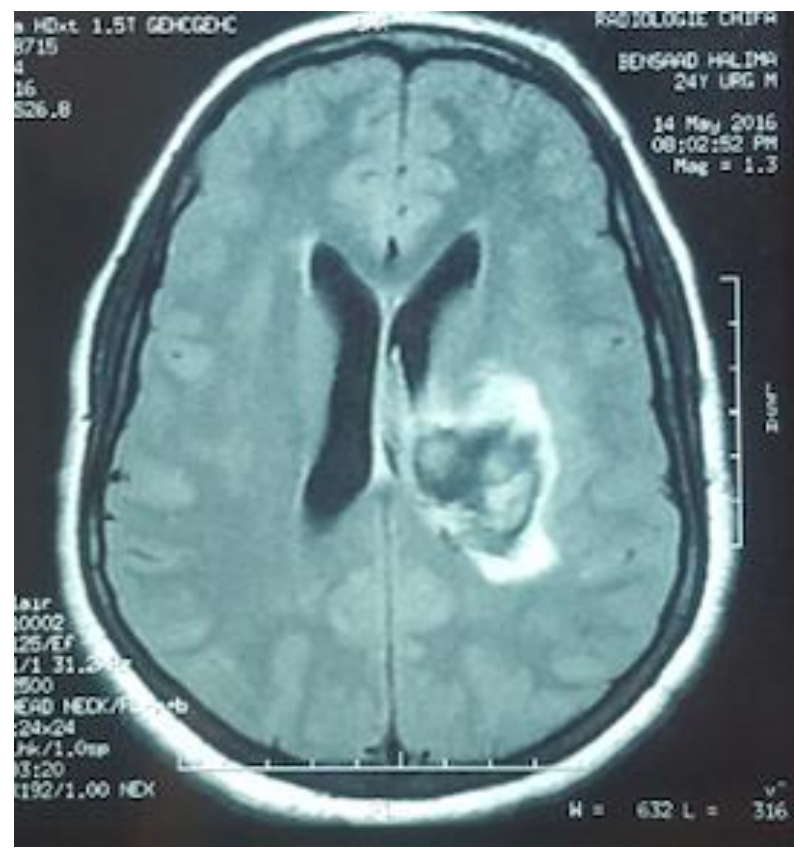

Fig-1: MRI in flair mode showing a deep left intraparenchymal parietal hematoma centered on the thalamus and near to the cerebral peduncle

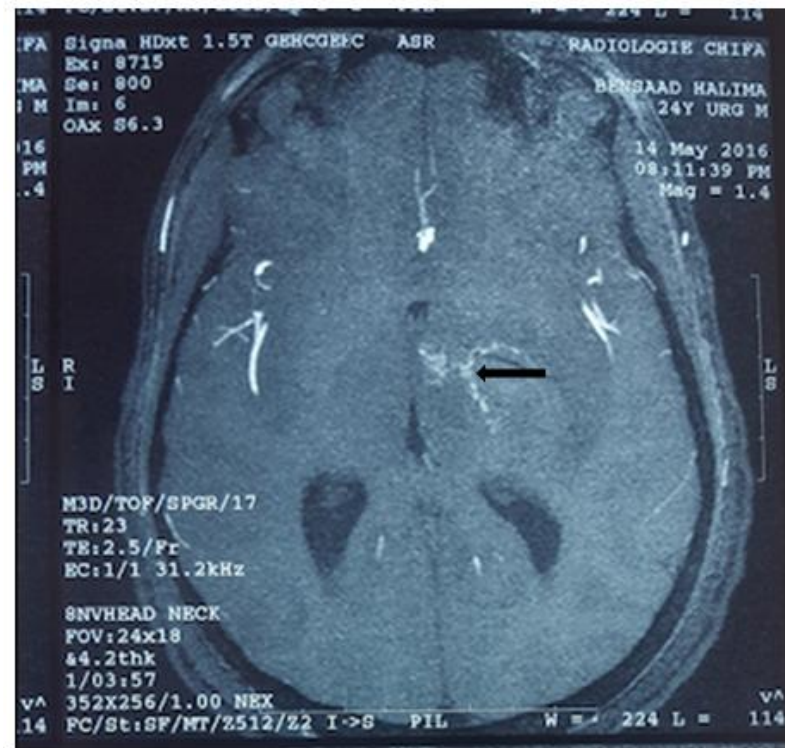

Fig-2: MRI angiography showing the AVM nidus ( black arrow) made up of multiple small serpiginous arterioles in the center of the hematoma

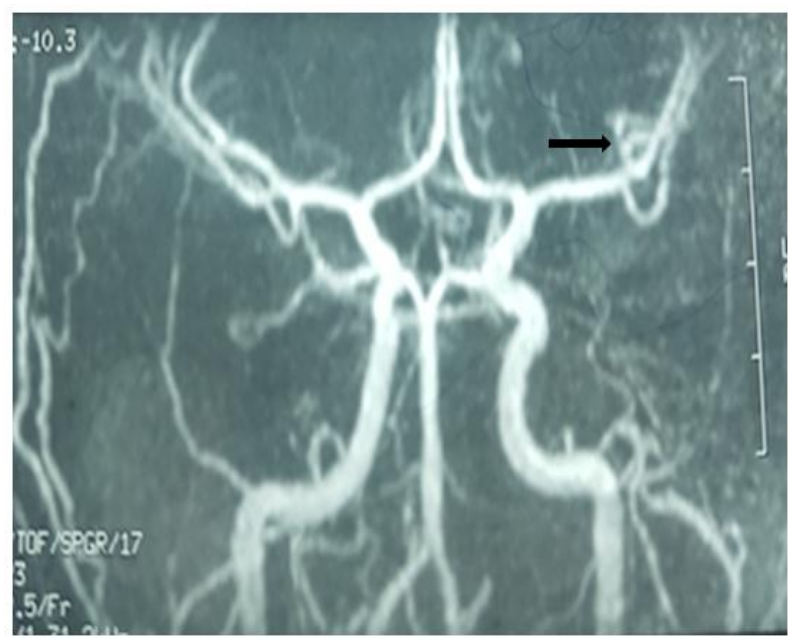

Fig-3: Angio MRI showing the AVM nidus (black arrow) supplied by the medial branch of the left posterior cerebral artery

\section{DISCUSSION}

The time of hemorrhage due to AVM in pregnant women is most common at the 15th-20th weeks in younger patients but bleeding may ocur at any stage including during labour or in the puerperium [5].

In our case, the patient was symptomatic at the 22 week of gestation. The uterine contractions of labour and the Valsalva effect of vaginal delivery are accompanied by dramatic, transient increases in venous pressure, cardiac output, and cerebrospinal fluid pressure. For this reason, Caesarean section is recommended for patients with inoperable AVMs [3]. The fundamental aims of anesthesia are to maintain oxygenation and stable systemic, cerebral and placental hemodynamics and to avoid increased intracranial pressure [6]. The most important problem in anesthetic 
management for the pregnant that has an emergency Caesarean section and AVM who can re-bleeding by hypertensive peak. The regional anesthetic technique could be preferred because it avoids the haemodynamic stress associated with laryngoscopy, intubation and extubation during general anesthesia [4, 7] and epidural anesthesia with titrated administration lidocaine and sufentanyl, decreases the risk of arterial hypotension compared to classic spinal anesthesia [8] and allows effective early postoperative analgesia [9]. The emergency of our case, general anesthesia was preferred, and haemodynamic stress during induction was prevented by using fentanyl, lidocaine and propofol. Coskun has also preferred general anesthesia to prevent haemodynamic stress, he used during induction in addition to lidocaine and propofol, a nitroglycerin $(0.5 \mu \mathrm{g} \mathrm{kg}-1 \mathrm{~min}-1)$, and remifentanil $(0.1$ $\mu \mathrm{g} \mathrm{kg-1min-1)}$ [10]. Concerning the maintenance of anesthesia in our case we used propofol in Targetcontrolled intravenous anesthesia with invasive monitorization of arterial blood pressure to ensure a stable anesthesia that helps prevent hemodynamic variations, allow intra-cranial pressure and the uteroplacental perfusion at appropriate levels, and a calm awakening allowing extubation in the best conditions [7].

\section{Conclusions}

Patients with symptomatic AVM during pregnancy are challenging in terms of medical approach in general, and of anesthetic management in particular in the absence of consensus the anesthetic technique should be discussed on a case-by-case.

\section{Abbreviations}

AVM: arteriovenous malformation, GCS: glasgow score, GA: gestationnel age, BP: blood pressure

\section{Acknowledgements: None.}

Funding: None.

Availability of data and materials : Relevant data and supporting materials will be made available on request.

\section{Authors' Contributions \\ MS and SK drafted the manuscript under the supervision of MB. All authors participated in patient care. All authors critically revised the manuscript, and all authors read and approved the final manuscript.}

Competing interests: The authors declare that they have no competing interests.

\section{Consent for publication}

Written informed consent was obtained from the patient for publication of this case report and any accompanying images.

Ethics approval and consent to participate: Not applicable.

\section{REFERENCES}

1. Riviello C, Ammannati F, Bordi L, Lamassa M, Mennonna P, Parretti E, Tondi F, Mello G. Pregnancy and subarachnoid hemorrhage: a case report. The Journal of Maternal-Fetal \& Neonatal Medicine. 2004 Jan 1;16(4):245-6.

2. Viscomi CM, Wilson J, Bernstein I. Anesthetic management of a parturient with an incompletely resected cerebral arteriovenousmalformation. Regional Anaesthesia. 1997; 22:192-197.

3. Lanzino G, Jensen ME, Cappelletto B, Kassell NF. Arteriovenous malformations that rupture during pregnancy: a management dilemma. Acta neurochirurgica. 1994 Jun 1;126(2-4):102-6.

4. Laidler JA, Jackson IJ, Redfern N. The management of Caesarean section in a patient with an intracranial arteriovenous malformation. Anaesthesia. 1989; 44:490-491

5. Wilkins RH. Natural history of intracranial vascular malformation: A review. Neurosurgery. $1985 ; 16: 421-430$.

6. Jaeger K, Ruschulte H, Mühlhaus K, Tatagiba M. Combined emergency Caesarean section and intracerebral aneurysm clipping. Anaesthesia. 2000 Nov;55(11):1138-40.

7. Yih PSW, Cheong KF. Anaesthesia for Caesarean section in a patient with an intracranial arteriovenous malformation. Anaesth Intensive Care. 1999; 27:66-68.

8. Carvalho CS, Resende F, Centeno MJ, Ribeiro I, Moreira J. Anesthetic approach of pregnant woman with cerebral arteriovenous malformation and subarachnoid hemorrhage during pregnancy: case report. Brazilian Journal of Anesthesiology (English Edition). 2013 Mar 1;63(2):223-6.

9. Sharma SK, Herrera ER, Sidawi JE, Leveno KJ. The pregnant patient with an intracranial arteriovenous malformation. Cesarean or vaginal delivery using regional or general anesthesia? Reg Anesth. Sep-Oct 1995; 20(5):455-8.

10. Coskun D, Mahli A, Yilmaz Z, Cizmeci P. Anesthetic management of caesarean section of a pregnant woman with cerebral arteriovenous malformation: a case report. Cases journal. 2008 Dec;1(1):1-3. 